\title{
Espartan@s de medicina interna
}

Julio Montes Santiago

Servicio de Medicina Interna. Hospital Álvaro Cunqueiro. EOXI. Vigo.

\section{Sabemos que moriremos jóvenes.}

Sabíamos que cuando nos arrojamos a bracear en este mar de la Medicina Interna, las penurias serían muchas, las angustias dilatadas, las jornadas de trabajo eternas. Pero nuestros pacientes nunca serían abandonados a sus penurias, a sus angustias, a sus infinitos temores.

Los reconocimientos, con excesiva frecuencia, serían parcos. Lo sabíamos. Y nuestra paga, la mayoría de veces, la satisfacción íntima de haber ayudado a nuestros semejantes más necesitados de la mejor forma posible. Pero ahora estamos convencidos de que moriremos jóvenes.

Porque es posible ser "super internista" un día, una semana, un mes..., pero no eternamente. Porque, como dijo el creador de aquel inmortal Quijote, las ansias crecen, las esperanzas menguan, y las fuerzas se agotan. $Y$ todo ello apenas sin apenas ruido, conscientes de un destino asumido. Aunque, a veces, en consideración de las miserias propias de nuestro estado, torzamos un gesto. $Y$ hasta puede que se nos escape un grito.

Porque no somos robots, porque nos hiere las entrañas el trabajo en esas condiciones de humillación -consultas interminables, interconsultas infinitas, ingresos crecientes, guardias interminables prolongadas al día siguiente, derivación continua de pacientes: porque "ya no puedo yo hacer nada"; porque mi servicio tiene numerus clausus; porque se me ocurre ahora que mi paciente que llega al ocaso de su vida y tras múltiples años de atención, es "pluripatológico"; porque no sé lo que tiene -y esto tampoco se confiesa- parece poco interesante averiguar- lo, porque -eso por supuesto no se dice-, me preocupan los números de mis estancias y a ver si cuela; porque, porque, porque...-

Pero todo ello, y en tropel, hace que sangremos en nuestro ánimo y las relaciones con los nuestros se resientan, y la irritabilidad que produce la extenuación nos haga a veces perder la amabilidad...

Sabemos que moriremos jóvenes. Pero los directivos siguen cómodos. Hemos hecho muchas promesas que -hemos descubierto- ison tan fáciles de incumplir! Es muy inconveniente darse una vuelta por una planta, por una consulta... No sea que est@s de la Medicina interna tengan razón en lo que dicen. Ojos que no ven... Y la nave hospitalaria sigue navegando. Y qué bien sigue funcionando. Son hombres y mujeres de anchas espaldas, que a pesar de que alguna vez se retuercen, jamás abandonarán a sus semejantes que les encomendamos. $Y$ todo seguirá su curso.

Por eso sabemos que moriremos jóvenes. Aunque con la dignidad, trágica, de aquellos héroes de Esparta.

Pero, al menos, que quede mínima constancia, en tan frágil soporte como la palabra escrita, no para nuestros superiores, cuyas entrañas están necrotizadas, pero sí para nosotros mismos y para aquellos a quienes ayudamos, que existió un tiempo moderno de héroes, que dieron hasta su último aliento para que ellos sanaran.

$Y$, aunque murieron jóvenes, SUS NOMBRES NO SE PERDIERON EN EL VIENTO DEL OLVIDO. 